\title{
IDENTIDAD PERSONAL Y CRITERIOS DE MUERTE ${ }^{1}$
}

\begin{abstract}
Alfonso Gómez-Lobo
En este trabajo se examina primero el concepto de identidad a través del tiempo y la diversidad de criterios que se han propuesto para decidir si hay o no identidad. En seguida se establece una correlación entre tres criterios de identidad personal a través del tiempo y tres criterios propuestos para decidir cuándo un ser humano ha muerto. Al criterio psicológico que requiere continuidad de experiencias mentales, sobre todo de memoria, corresponde la disfuncionalidad neo-cortical: se sostiene que la persona ha dejado de existir cuando ha perdido irreversiblemente la conciencia. A la así llamada "muerte cerebral total” como criterio de muerte le corresponde la idea de que somos un compuesto de cerebro y cuerpo y que el cerebro es el integrador de las funciones somáticas. La evidencia empírica de que a la "muerte cerebral total” no le sigue necesariamente un colapso de la totalidad de las funciones
\end{abstract}

Alfonso Gómez-Lobo. Ph.D. en filosofía, filología clásica e historia antigua. Estudió en Valparaíso, Atenas, Tubinga, Munich (donde obtuvo el doctorado) y Heidelberg. Profesor titular de la cátedra Ryan de Metafísica y Filosofía Moral de la Universidad de Georgetown y miembro del Consejo de Bioética de la Casa Blanca, Washington, D.C. Actualmente es también profesor en el Instituto de Filosofía y en el Centro de Bioética de la Universidad Católica de Chile. Miembro del Consejo Directivo del CEP.

${ }^{1}$ Texto revisado de una conferencia dictada el 29 de abril 2009 en el CEP.

Estudios Públicos, 114 (otoño 2009). 
somáticas ha llevado a dudar de que el cerebro ejerza la función integradora central. Ésta sería mucho más difusa y correspondería más bien a la activación que ejerce el genoma. En la actualidad esto nos obliga a volver al paro cardio-pulmonar como la manera más confiable de saber que alguien ha muerto.

Palabras clave: Barco de Teseo, identidad, identidad personal, criterios de muerte, muerte cerebral.

$\mathbf{E}_{\text {xiste un viejo reproche a la actividad filosófica, expresado }}$ por Calicles, un interlocutor de Sócrates, quien dice que cuando se es muy joven y se lo hace para adquirir “cultura” está bien dedicarse a la filosofía, pero cuando un hombre ya maduro todavía filosofa, la cosa se pone ridícula ${ }^{2}$.

En efecto, las personas adultas que practican otras disciplinas se hacen preguntas responsables y serias que todos reconocemos como tales. Un médico se pregunta si un enfermo evolucionará favorablemente luego de cierto tratamiento intensivo y un biólogo se interroga acerca de las implicaciones futuras de una cierta mutación genética. Algunos filósofos, en cambio, se preguntan si Sócrates y Sócrates sentado son un mismo objeto o son dos, o si ha dejado de ser Sócrates por haber tomado asiento ${ }^{3}$. A primera vista se trata de preguntas frívolas y ociosas que se merecen plenamente y en justicia el reproche de Calicles.

Estas preguntas pueden ser caracterizadas como preguntas por la identidad o alteridad, y también como preguntas por la unidad y la multiplicidad. Si algo es idéntico a sí mismo, entonces es un solo objeto. Si no hay identidad, entonces hay más de un objeto, hay multiplicidad y por ende alteridad: el uno no es el otro.

Lo que trataré de hacer en esta exposición es primero formular de la manera más simple posible los problemas generales que suscita la noción de identidad para luego examinarlos en el caso más particular de las personas. Espero poder mostrar que lejos de tratarse de preguntas

\footnotetext{
2 Platón, Gorgias 485a.

${ }^{3}$ El primero de estos ejemplos aparece literalmente en Aristóteles, Metafísica
} IV. 2. 1004b 2-3. 
frívolas se trata de preguntas de enorme importancia para nuestra cultura contemporánea. Trataré de mostrar además que ciertos desarrollos científicos recientes nos permiten ofrecer algunas respuestas que les estaban vedadas a los filósofos de generaciones previas a la nuestra. No quisiera, con todo, que se perdiera de vista el carácter exploratorio de lo expresado aquí y por ende susceptible de complementación o rechazo por parte de quienes saben más que yo de estas cosas.

Para plantear el problema, como siempre, conviene partir por los griegos. Plutarco de Queronea, una polis de Beocia, fue un prolífico autor del siglo I de nuestra era que escribió vidas paralelas de griegos y romanos ilustres. En su vida del gran héroe Teseo menciona una perplejidad o aporía que dividía a los filósofos de su época ${ }^{4}$.

Para entenderla reconstruyamos el contexto. Estamos en el segundo milenio antes de nuestra era, en la vaga frontera entre mito e historia. Los atenienses están bajo el yugo de Minos, rey de Creta, poseedor de una poderosa flota, la famosa talasocracia cretense. Como parte de los tributos que le han sido impuestos, Atenas debe enviar periódicamente siete doncellas y siete jóvenes que serán sacrificados al Minotauro, el monstruoso príncipe de Cnosos que es mitad toro y mitad hombre. Teseo ofrece embarcarse con los dìs heptá, “dos veces siete”, logra matar al Minotauro y con la ayuda de Ariadna escapa del laberinto, liberando así a los atenienses de la dominación cretense ${ }^{5}$.

Con justa razón el barco de Teseo fue considerado sagrado y los atenienses lo enviaban todos los años a la isla de Delos para ofrecer sacrificios de gratitud a Apolo. Como era de esperar, con el tiempo muchas planchas del barco de madera se fueron pudriendo y hubo que reemplazarlas para que el barco pudiese seguir navegando. Cuenta Plutarco que los filósofos de su época disputaban acerca de si el barco anclado en ese momento en el Pireo, una vez reemplazadas todas las tablas, era el mismo barco de Teseo o no. Se le atribuye al filósofo inglés Thomas Hobbes el haberle dado un nuevo e ingenioso giro a la

\footnotetext{
${ }^{4}$ Plutarco, Vida de Teseo 23.1.

${ }^{5}$ Platón, Fedón 58a - b.
} 
disputa al sugerir que las planchas viejas pudieron ser conservadas y que con ellas se habría reconstruido el antiguo barco ${ }^{6}$. Supongamos que los atenienses le han asignado un lugar especial entre los monumentos que hay en el ágora de Atenas.

Tenemos entonces tres navíos: (A) el barco original en que navegó Teseo, (B) el barco que aún navega, pero está completamente renovado, y (C) el barco reconstruido en tierra con los materiales originales. Las preguntas pertinentes son las siguientes: puesto que B y C obviamente no pueden ser idénticos, pues uno está en el Pireo y el otro en el ágora, ¿es A idéntico a $\mathrm{B}$ ? ¿O es A idéntico a C?

Cuando uno les hace sin previo aviso estas preguntas a personas que las oyen por vez primera, las respuestas suelen dividirse, aunque en general me he encontrado con una tendencia a favorecer la identidad de A con C. Pero para poder ir más allá de una adivinanza intuitiva y poder adelantar una solución racional se requiere algo así como un criterio para poder decidir si hay o no identidad, dicho más brevemente, un criterio de identidad. Por ejemplo, si un criterio de identidad aceptable es estar compuesto por el mismo material, entonces A será idéntico a C. Son al fin y al cabo las mismas tablas y planchas las que formaban parte del barco original y ahora del barco reconstruido en el ágora.

Pero esta solución debe enfrentar una objeción: hubo una interrupción o discontinuidad entre A y C tal que podemos hablar de una multiplicidad, es decir, de más de un navío: el barco originario y el barco que fue reconstruido tal vez siglos después. Se trata a todas luces de dos barcos pues hay un vacío o hueco espacio-temporal entre ambos. Esta objeción está fundada de hecho en un criterio de identidad que sostiene que si hay continuidad espacio-temporal entre dos objetos, se trata del mismo objeto. Pensemos en una mesa de billar donde hay dos bolas blancas exactamente iguales en distintas posiciones. Las llamaremos D y E. En seguida damos la espalda a la mesa, alguien mueve las bolas de billar a otras posiciones y ahora las llamamos F y G. Al preguntarnos si D es F o G echamos mano a la idea de que si D tuvo un recorrido sobre la mesa que la llevó a la posición en que ahora está $\mathrm{F}$ entonces diremos que $\mathrm{D}$ es $\mathrm{F}$, que $\mathrm{D}$ es idéntica a $\mathrm{F}$ o la misma bola que F. Si se hizo, por ejemplo, un video mientras estábamos de espaldas, dicho video, al mostrarnos el recorrido de la bola de billar D, confirmará su identidad con F.

${ }^{6}$ Hobbes, De Corpore 2. 11. 7. 
En el caso que estamos examinando es sin duda B, el barco que está anclado en el Pireo y que aun navega todos los años a Creta, el que conserva la continuidad espacio-temporal con A, el barco en que antaño navegó Teseo.

Hemos llegado a una perplejidad o aporía, pues dado que B no es idéntico a $\mathrm{C}$, una y sólo una de las respuestas puede ser la correcta. ¿Qué hacer?

Una primera medida consiste en examinar los criterios de identidad aducidos. Un criterio es, como sugiere su raíz griega, algo así como un cedazo, un instrumento para separar líquidos de sólidos. Si su trama es muy densa retendrá más líquido de lo que quisiéramos y si sus agujeros son muy grandes dejará pasar algunos sólidos que queremos retener. En otras palabras, un criterio o estándar es un instrumento que escogemos y que puede resultar apto o inepto. Para juzgar si un criterio es adecuado o no tenemos que apoyarnos en otras consideraciones que en el caso de la identidad no pueden ser sino intuitivas. No podemos deducirlas.

Explico lo anterior. Si un mecánico desmonta el motor de un auto para limpiarlo y luego lo rearma dejándolo tal como era antes, diremos, sin poder probarlo, que se trata del mismo motor. Sería contraintuitivo decir que se trata de otro motor, que en dos momentos del tiempo el mecánico tuvo en sus manos dos motores distintos. Lo mismo ocurre con cualquier objeto susceptible de ser desarmado y rearmado, como un librero o un computador, siempre que se utilicen exactamente sus mismos componentes. Tal vez se trata de algo que ocurre con muchos artefactos. De aquí podemos colegir que el criterio de identidad basado en identidad de componentes es un criterio adecuado, pero, se debe agregar, para cierto tipo de artefactos, para aquellos con una constitución estática, como un librero o un puente.

Hay en cambio artefactos que no se limitan a estar allí, inertes, sino que tienen un comportamiento dinámico. Si consideramos esa función o actividad característica, lo que en griego aristotélico se llamaría su érgon o su enérgeia, es probable que resulte intuitivamente plausible la idea de que una sustitución de componentes, no sólo selectiva sino incluso masiva, no afectará su identidad ${ }^{7}$. Al aumentar drásti-

${ }^{7}$ Las nociones de érgon y de enérgeia juegan un papel muy importante en todo el pensamiento de Aristóteles. Los pasajes más importantes pueden ser encontrados fácilmente utilizando Höffe (2005), s. v. enérgeia y érgon. 
camente la memoria de mi computador, no paso a tener otro, sino el mismo, mejorado. Si el érgon de un barco es navegar, entonces el barco que ha seguido navegando a Delos es el barco de Teseo aunque sus componentes hayan sido todos sustituidos. Hemos vuelto a la aporía anterior, pero con una pequeña ventaja: ahora vemos que la verdad o falsedad de un enunciado de identidad depende de la clase o tipo de cosas de que se trate. A puede ser el mismo barco que B sin que A sea el mismo conjunto de tablas que B. La clase o el tipo de cosas lo expresamos mediante un término que apunta a un concepto bajo el cual pensamos que cae el objeto en cuestión. Hablaré simplemente de un término y de un concepto substancial S. La pregunta por la identidad es, entonces, en su fórmula más general: ¿es x el mismo S que $y ?^{8}$

\section{II}

Ahora daré un salto hacia la filosofía moderna y contemporánea y preguntaré por la identidad de las personas.

En este contexto hay un uso de la expresión "la identidad de una persona" que no logro entender cabalmente y que quisiera dejar de lado. A veces se dice, por ejemplo, que el pueblo aimara está perdiendo su identidad, o que el haber sido pianista es parte de la identidad de Claudio Arrau, con la implicación de que si hubiese sido futbolista en vez de músico habría sido otra persona. No me refiero a esta noción de identidad personal sino a aquella que se afirma cuando alguien dice, por ejemplo, "el niño que aparece en la vieja fotografía es mi abuelo".

¿Cuál es el criterio adecuado para decidir la identidad de personas en distintos momentos del tiempo? Como problema filosófico éste fue inaugurado por John Locke y su solución ha tenido muchos adeptos en las últimas décadas, incluso entre pensadores que al abordar otros problemas hacen uso de ella aunque no lo admitan expresamente.

La solución a la cual me refiero es la concentración en la vida mental característica de las personas, la cual arroja el siguiente criterio: la persona $\mathrm{P}$ es la misma que la persona $\mathrm{Q}$, situadas éstas en distintos momentos del tiempo, si y sólo si hay una continuidad en las experien-

${ }^{8}$ Véase Wiggins (2001), pp. 1-192. 
cias mentales de $\mathrm{P}$ y $\mathrm{Q}$. Si yo $\mathrm{Q}$ tengo recuerdos que me ligan ininterrumpidamente con algo que experimentó $\mathrm{P}$, entonces soy $\mathrm{P}^{9}$.

Hagamos algunas observaciones. En primer lugar hay que hacer notar el trasfondo cartesiano de este criterio $^{10}$. Descansa sin duda sobre una distinción significativa entre cuerpo y alma, y esta última es el sujeto de experiencias tanto perceptivas y sensitivas como intelectivas. Soy yo quien percibe, recuerda y piensa, es decir, quien está consciente de todas esas experiencias que constituyen la mente, y yo soy mi mente.

Que por ende yo sea una res cogitans, una substancia inmaterial y autosubsistente, que continuará existiendo al morir mi cuerpo (como pensaba Descartes), no es una inferencia compartida necesariamente por quienes defienden el criterio psicológico, como se lo llama hoy. Por el contrario, sostienen que mi mente, y por ende, yo, podría desaparecer antes de mi muerte, aunque hablar de "mi” muerte después de que he dejado de existir suene a paradoja.

Otra observación importante es que esta posición es también neo-cartesiana en cuanto adopta una perspectiva de primera persona singular. Veo el mundo desde mi perspectiva (yo pienso, cogito) y todo, el mundo entero, deja de existir si yo dejo de existir. Si no estoy yo allí como sujeto de experiencias ¿qué sentido tiene para mí hablar de un mundo no experimentado por mí?

El criterio psicológico opera entonces bajo el concepto substancial sujeto de experiencias conscientes. Esto es lo que cada uno de nosotros sería esencialmente y, por ende, lo que determinaría el criterio de identidad para los seres humanos.

Esta posición ha sido defendida con gran acopio de argumentos, algunos muy imaginativos pero a mi juicio con débil fuerza probatoria porque se trata de "experimentos de pensamiento" (thought experiments) que describen situaciones de cuya plausibilidad nada sabemos. Por ejemplo, si a un individuo se le seccionan los hemisferios cerebrales y el izquierdo es trasplantado a un cuerpo, mientras que el derecho a otro, conservando cada uno la memoria que estaría contenida íntegra en cada hemisferio, el resultado de esta “fisión” (lo opuesto a “fusión”)

${ }^{9}$ Véase Wiggins (2001), pp. 193-225; DeGrazia (2005), pp. 13-29.

${ }^{10}$ Las fuentes cartesianas con útiles comentarios pueden ser consultadas en Dicker (1993). 
¿sería una persona “doble”? ${ }^{11}$ Me parece que no poseemos ninguna evidencia empírica para poder extraer inferencias de alguna utilidad.

Existen en cambio viejas objeciones al criterio psicológico que tienen que ver con la falibilidad de la memoria. Si yo a los 25 recuerdo algo que hice a los 15 y a los cincuenta recuerdo lo que hice a los 25 pero he olvidado completamente lo hecho a los 15, ¿he dejado de ser la misma persona? Hay quienes sostienen que bastaría con "tramos" que se sobrepongan en sus respectivos extremos para garantizar identidad, pero esto es compatible con una sucesión episódica de personalidades. Por otra parte, si recuerdo algo hecho o padecido hace tiempo, bien podría tratarse de un recuerdo falso e ilusorio. Me contaron algo (o lo leí en un libro o lo vi en una película, etc.) y creo recordar haberlo padecido yo. Es conocida la capacidad de cualquier psicólogo hábil para elicitar en un niño recuerdos, por ejemplo, de experiencias de pedofilia que no ocurrieron.

¿Cómo distinguir entre memoria ilusoria y memoria auténtica? La condición mínima es la siguiente: un recuerdo será auténtico sólo si hay identidad entre mí hoy y el individuo en el pasado que tuvo esa experiencia que ahora recuerdo. Es decir, sólo suponiendo la identidad del sujeto de experiencias habrá una distinción posible entre recuerdo falaz y recuerdo verdadero. Por lo tanto, la memoria por sí sola no provee un criterio confiable de identidad personal. Al contrario la confiabilidad de la memoria supone como condición necesaria la identidad de la persona.

Pero además de ser muy frecuentemente falaz, la memoria es tan vulnerable que puede en determinados casos perderse totalmente. La amnesia total es una condición patológica que pone a una persona situaciones vitales muy difíciles de manejar. Por ejemplo, si una persona que ahora es amnésica total cometió un crimen, ¿es justo castigarla puesto que no tiene ninguna conciencia de lo hecho? Hay defensores del criterio psicológico que dirán que a esa persona no se la debe castigar precisamente porque estamos ante un caso en que una persona dejó de existir y comienza a existir otra. Pero ¿qué diremos si la segunda persona paulatinamente va emergiendo de la amnesia total y comienza recordar acontecimientos de su vida pasada? Pero para siquiera hablar de "acontecimientos de SU vida pasada" y, por ende, para

${ }^{11}$ Argumentos de esta índole han sido propuestos por Derek Parfit. Véase DeGrazia (2005), pp. 15-27. 
poder diagnosticar el grado de la condición patológica hay que suponer nuevamente una identidad. Una vez más resulta que el criterio psicológico garantizado por la memoria no es confiable.

¿Por qué nos interesa decidir si el criterio psicológico es adecuado o no? Hace un momento señalábamos que un juicio de identidad requiere de un concepto $S$ bajo el cual la identidad es posible: A es el mismo navío que $\mathrm{B}$, pero no puede ser la misma carreta que $\mathrm{F}$ porque A es esencialmente un navío, y no un medio de transporte terrestre.

El criterio psicológico supone que somos esencialmente sujetos conscientes de experiencias mentales. Esto a su vez tiene decisivas consecuencias para un acuciante problema contemporáneo.

\section{III}

En la actualidad, como es sabido, el trasplante de órganos ha hecho enormes progresos y en todas partes donde esta técnica médica se practica existe un desajuste entre demanda y oferta. En EE.UU. en un año hay aproximadamente 90.000 pacientes en lista de espera para un trasplante y normalmente se obtienen cerca de 40.000 órganos ${ }^{12}$. En Chile hemos vivido recientemente el drama generado por la falta de un donante de corazón para un niño (Felipe Cruzat).

La necesidad de obtener órganos viables originó desde los comienzos de la práctica de los trasplantes un debate en los siguientes términos: si una persona muere y transcurre un tiempo entre su muerte y la extracción de sus órganos, éstos normalmente no servirán para ser trasplantados porque una vez que el paciente ha dejado de respirar y su sangre ha dejado de circular, los órganos inician el ineludible proceso de putrefacción. Pero, si bien el paro cardio-pulmonar es un innegable indicio de que la persona está muerta, ¿̇no ocurrirá que ese paro es precisamente un indicio, vale decir, una consecuencia de algo que sucedió antes? Ese acontecimiento anterior sería la muerte misma. La pregunta se agudiza si a esto se agrega el uso del respirador, es decir, de una máquina capaz de postergar el paro circulatorio y respiratorio pues mientras los pulmones reciban oxígeno y éste sea transportado

12 Esta información proviene de las deliberaciones del Consejo Presidencial de Bioética de EE.UU. (President's Council on Bioethics (2009) Puede obtenerse en www.bioethics.gov/topics/organ_index.html. 
hasta el corazón, éste seguirá latiendo. ¿Está viva esa persona o simplemente se han inhibido los indicios de su muerte ya acaecida? ${ }^{13}$

Estas preguntas han suscitado un intenso debate sobre la "definición” de muerte. A mi juicio, es un error filosófico hablar de un cambio de la "definición” de la muerte. Una definición asigna un significado a un término. Si la definición cambia por lo general cambia también el referente, y por ende pasamos a hablar de otra cosa. Si desde ahora definimos "triángulo" como "una figura plana de cuatro lados" ya no estaremos hablando de lo que ahora llamamos "un triángulo" sino de un cuadrilátero. Si cambiamos la definición de "muerte” corremos el riesgo de hablar de otra cosa.

El debate, en realidad, ha sido no sobre la definición sino sobre los criterios de muerte. Tal como nos preguntábamos “¿cómo decidir si un barco A es o no idéntico a un barco B?”, ahora nos preguntamos “¿cómo decidir si un paciente ha muerto o no?”

Hay quienes responden en forma perfectamente consistente con el criterio psicológico de identidad: puesto que somos esencialmente sujetos de experiencias conscientes, sostienen que una vez perdida definitivamente la conciencia, hemos dejado de existir. Esto es precisamente lo que ocurre con pacientes que llegan al Estado Vegetativo Permanente (PVS, según sus siglas en inglés: Persistent Vegetative State). Ésta es una condición en que la zona neocortical del cerebro ha dejado de funcionar (por ejemplo, por falta de irrigación sanguínea o isquemia) y debido a ello la persona ha perdido completamente la capacidad para recibir, o ser sujeto de sensaciones, percepciones o pensamientos. Según el criterio de identidad que estamos examinando, se sigue que no hay identidad entre la persona antes de perder definitivamente la conciencia y la paciente que yace ahora inconsciente en el lecho.

Muchos filósofos aceptan esta conclusión, pero deben enfrentar serias objeciones. Basta con recordar los dramáticos casos de dos personas en PVS que han estado recientemente en las primeras páginas de la prensa mundial: Terry Schiavo en EE.UU. y Eluana Englaro en Italia. En ambos casos la disputa fue acerca de si se debía o no continuar con su nutrición e hidratación por medios tecnológicos. La disputa misma sólo tiene sentido sobre el supuesto de que ambas

${ }^{13}$ Véase The President’s Council on Bioethics (2009). 
estaban con vida y que dejaron de existir al suspenderse su nutrición, es decir, años después de que perdieron la conciencia. El criterio psicológico de identidad obligaría por lo tanto a reconocer dos muertes: la muerte de la persona y la muerte de su cuerpo. Pero puesto que un organismo no puede morir sino una sola vez, tendremos que admitir que sólo suponiendo un dualismo substancial se puede dar cuenta del fenómeno. Sólo dos substancias distintas pueden dejar de existir en distintos momentos del tiempo ${ }^{14}$.

La teoría de las dos muertes parece ser tan claramente inaceptable que de hecho, y pese a que ha tenido importante apoyo filosófico, ninguna jurisdicción del mundo anglosajón (ni del resto del mundo, hasta donde estoy informado) ha aceptado como criterio legal de muerte la cesación permanente de la conciencia. Salvo en aquellos lugares en que todavía se declara la muerte sobre la base de paro cardiopulmonar irreversible, el criterio generalmente aceptado es el de disfunción cerebral total. Esta última observación nos conducirá a una nueva exploración filosófica de la identidad personal.

\section{IV}

El criterio de muerte neocortical, es decir, la idea de declarar muerta a una persona por el hecho de haber perdido irremisiblemente la conciencia (aunque ella siga respirando y su corazón latiendo) es en realidad una nueva etapa dentro de un desarrollo iniciado mucho antes.

En 1959 un equipo francés liderado por P. Mollaret y M. Goulon había llamado coma depassé a un síndrome caracterizado por la pérdida de toda reacción refleja y de toda actividad cerebral en pacientes cuya actividad cardio-pulmonar podía ser mantenida a pesar de la pérdida irreversible de la conciencia ${ }^{15}$.

Unos pocos años después se formó el famoso Comité Ad Hoc de la Escuela de Medicina de la Universidad de Harvard presidido por el Dr. Henry Beecher, que en 1968 emitió un informe en que se formulaba el criterio de "muerte cerebral total" como una nueva "definición" de la muerte ${ }^{16}$. No sólo es erróneo, como lo señalábamos, hablar de una

\footnotetext{
${ }^{14}$ Entre quienes aceptan estas consecuencias está Jeff McMahan. Véase McMahan (2002), pp. 424-425.

${ }^{15}$ Mollaret \& Goulon (1959).

${ }^{16}$ Ad Hoc Committee (1968).
} 
nueva definición de muerte, sino que también lo es el sostener que la muerte de un organismo equivale a la "muerte" de uno de sus órganos. Pese a estos defectos conceptuales y al hecho de no incluir ningún tipo de explicación o fundamentación filosófica, el informe del Comité Beecher tuvo gran influencia y aun hoy se habla de "muerte cerebral" cuando se quiere describir la condición de un paciente cuyos órganos pueden ser extraídos lícitamente.

El paso decisivo vino en 1981 con la publicación de un informe de la Comisión Presidencial de EE.UU. para el Estudio de los Problemas Éticos en Medicina e Investigación Biomédica y Conductual, pues este informe incluía un modelo para formular leyes que fijaran los criterios de muerte. Este modelo fue luego adoptado por la totalidad de los estados que componen los EE.UU. ${ }^{17}$.

El modelo legal propuesto era bastante contemporizador pues proponía una disyunción: se puede declarar muerto a un individuo que ha sufrido un cese irreversible de las funciones circulatorias y respiratorias o bien que ha sufrido un cese irreversible de todas las funciones de la totalidad del cerebro, incluyendo el tronco.

El criterio disyuntivo (que es también el adoptado en Chile) tiene tanto la ventaja de respetar una actitud tradicional cuando no hay expectativas de un trasplante (simplemente se espera el paro cardiopulmonar) como también la de permitir medidas eficientes cuando se tiene la intención de realizar un trasplante (se hace uso de un respirador para que los órganos del cadáver se mantengan oxigenados).

Para nuestros fines, sin embargo, hay otro aspecto del informe de la Comisión Presidencial que resulta interesante: hay en él un esfuerzo por ofrecer una justificación filosófica del criterio propiamente neurológico de muerte, es decir, de la disfunción cerebral total.

La razón por la cual el criterio neurológico es válido o adecuado viene dada por dos premisas. La primera (1) es que la muerte debe ser entendida como la pérdida permanente e irreversible del funcionamiento integrado del organismo como un todo y la segunda (2) es que el cerebro es el órgano responsable de dicha integración. En su versión más simple esa integración consiste en que si bien el corazón late sin intervención del cerebro, en la medida en que la respiración depende de impulsos cerebrales, al fallar dichos impulsos y por ende la respiración,

${ }^{17}$ President’s Commission (1981). 
cesa de llegar oxígeno al corazón y éste se paraliza. Es por esto que al reemplazar la tendencia espontánea a respirar, cuando ésta falla, por una máquina que bombea aire, se puede mantener latiendo el corazón de lo que sería ya un cadáver que ha perdido la integración fundamental.

Las dos premisas aducidas para justificar la disfunción cerebral total como criterio neurológico de muerte fueron aceptadas desde un comienzo sin mucha discusión crítica. Fueron en realidad tomadas como un factum en el ámbito médico, bioético y político, lo cual contribuyó sin duda a su institucionalización legal en casi todas partes. Antes de mencionar las dificultades que han comenzado a surgir convendría, como ya hemos hecho con el criterio psicológico, dar un rodeo por la noción de identidad personal subyacente al criterio neurológico.

La noción de identidad lógicamente consistente con el criterio neurológico de muerte es, en principio, el siguiente: un individuo humano es el mismo individuo humano, aunque pierda no sólo la memoria sino la totalidad de la conciencia, si y sólo si tiene el mismo cerebro integrando las funciones somáticas de su organismo. Un hipotético trasplante de cerebro crearía una difícil disyuntiva: si la identidad la garantiza el cerebro, el cuerpo receptor del cerebro tendría que ser el que mantiene la identidad con el individuo donante del cerebro. Esto es precisamente lo que han sostenido desde siempre los defensores del criterio psicológico, con la diferencia obvia de que a su entender el garante de identidad sería el cerebro en cuanto sujeto de las memorias (y en general de los actos mentales) del donante. Para el criterio neurológico se trata del cerebro solamente en cuanto integrador somático.

Si intentamos sacar a luz los supuestos metafísicos de esta posición nos encontraremos una vez más con un dualismo, esta vez, un dualismo sui generis. En efecto, no se trata de un dualismo mentecuerpo en cualquiera de sus versiones, sino de un dualismo cerebrocuerpo.

Pero ¿no habremos entendido mal la posición que estamos describiendo? Por definición, si una substancia no implica necesariamente la desaparición de otra cosa se trata de dos substancias, pero aquí la relación se asemejaría a la que existe no entre dos substancias sino entre una substancia y sus propiedades: la disfuncionalidad del cerebro arrastraría consigo la pérdida de la integración del cuerpo, tal como la 
desaparición de Sócrates arrastra consigo la desaparición de la palidez de Sócrates.

Lo asombroso es que hay evidencias empíricas que muestran que eso no es así.

\section{V}

La más reciente etapa en la discusión del criterio de muerte, se inicia con las críticas Robert Veatch al criterio neurológico ${ }^{18}$. Según Veatch, en muchos casos de "muerte cerebral" no se puede ignorar la frecuente existencia de actividad residual en partes del cerebro y por eso es una utopía exigir un cese total de toda actividad en la totalidad del cerebro antes de declarar la muerte del paciente. Pero esto condujo a Veatch a la idea de muerte neo-cortical: bajo este criterio bastaría, como vimos, con la pérdida irrevocable de la conciencia para considerar muerto a un paciente que respira y tiene circulación sin ningún apoyo tecnológico.

Pero los problemas y vacíos conceptuales detectables en el criterio neurológico pueden conducir en otra dirección, pueden llevar a cuestionar uno de los supuestos mismos del criterio, a saber, la premisa de que el cerebro es el órgano integrador de las funciones somáticas. La verdad de esta premisa implicaría que cuando el cerebro deja de funcionar se sigue de inmediato la disrupción de todo el organismo, se siguen los indicios tradicionales de la muerte.

El neurólogo norteamericano Alan Shewmon ha cuestionado esto último y ha logrado encontrar evidencia empírica de que 175 pacientes declarados en muerte cerebral han seguido exhibiendo funciones vitales, algunos por unos días o meses, pero algunos también por años ${ }^{19}$. El caso extremo es el de un niño (TK) nacido en 1979 cuyo cerebro fue destruido por una meningitis aguda a los cuatro años y sobrevivió, con apoyo vital, hasta los 24. Estos hallazgos han resultado tan chocantes frente a las convicciones establecidas que inicialmente se cuestionó el diagnóstico de muerte cerebral, especialmente en el caso más extremo, pero ahora, con la publicación de la autopsia hecha por un equipo de patólogos independientes, se ha confirmado que efectivamente TK estuvo durante 16 años sin actividad cerebral alguna ${ }^{20}$.

\footnotetext{
${ }^{18}$ Veatch (1993).

${ }^{19}$ Shewmon (1998) y Shewmon (2001).

${ }^{20}$ Repertinger et al. (2006).
} 
Existe otra alternativa para defender el statu quo frente al desafío que presentan estos casos, a saber, el interpretar la aparente sobrevivencia como actividad de subsistemas del organismo sin integración total. Esta estrategia equivale a reafirmar la primera premisa que justifica el criterio neurológico. La vida supone integración de la totalidad del organismo y esto no se daría, según los defensores del criterio neurológico, en el caso, por ejemplo, de TK. A esto Shewmon ha respondido con una larga enumeración de fenómenos (crecimiento proporcionado, homeostasis, excreción de residuos, coordinación inmunológica, etc.) que deben ser entendidos como funciones holísticas, es decir, del organismo como un todo. Dentro de mi limitada experiencia, me atrevería a decir que esta es una zona donde la investigación empírica es la que permitirá dirimir más adecuadamente el problema fisiológico central: ¿cuál es exactamente el papel del cerebro dentro de la integración orgánica? ¿Se trata de un órgano que impone un orden en forma vertical (top-down es la expresión que emplea Shewmon) sobre una colección multifacética de órganos y que por lo tanto constituye el centro de la vida? ¿O debemos pensar que no hay un centro localizable de la vida sino que ésta se encuentra difusa por todo el organismo?

\section{VI}

Esta última sugerencia nos lleva a reformular las preguntas que hemos estado tratando de responder desde el comienzo.

Si no somos esencialmente sujetos de experiencias conscientes, entonces ¿qué somos? ¿Cuál es ese concepto $\mathrm{S}$ bajo el cual una persona consciente sigue siendo la misma persona que ahora está inconsciente, como suponemos intuitivamente? Si no somos esencialmente cerebros que imponen orden a sus cuerpos como los estrategos griegos imponían orden en las filas de sus hoplitas, entonces ¿qué somos?

En la metafísica anglosajona reciente algunos filósofos jóvenes han hecho un giro hacia una posición a la vez más simple y más tradicional. Han comenzado a hablar de un criterio biológico de identidad personal y lo que quieren decir con esto es que somos esencialmente organismos o cuerpos vivos ${ }^{21}$. Una persona que vemos ahora es

${ }^{21}$ Los representantes más destacados de esta posición son Olson (1997) y DeGrazia (2005). 
la misma persona que vimos el año pasado no porque ella recuerde lo que hizo entonces (puede haber caído en amnesia total o haber entrado a la demencia senil) sino porque nosotros podemos reidentificar su cuerpo.

Nótese en primer lugar que se ha abandonado la perspectiva neo-cartesiana de la primera persona singular. Somos los demás, como observadores externos, los que podemos decir que se trata de la misma persona aunque ella no esté en condiciones de hacer este reconocimiento. La perspectiva no es sólo de primera persona plural, sino que es de partida perfectamente holística. No identificamos a nadie con uno de sus órganos, por importante y crítico que éste sea.

Ahora bien, la identidad del cuerpo en el tiempo presenta dificultades que ya Platón hacía notar: hay una renovación constante de los componentes materiales a tal punto que se suele decir (no con mucha exactitud) que todas nuestras células se renuevan completamente dentro de un par de años ${ }^{22}$. En este sentido nuestro cuerpo equivaldría al barco C de Teseo. Pero existe una diferencia fundamental entre un navío y un organismo. Al navío le asignamos desde fuera un érgon o una enérgeia, una actividad, el navegar, que es, en realidad, una actividad nuestra, es decir, externa al barco mismo. Un organismo en cambio posee una actividad intrínseca, su vida misma, que se autorregula y extiende en el tiempo.

Con esto llegamos al avance científico que mencioné al comienzo: a la genética actual. Hoy se sabe que la información activante de un organismo está constituida por el código genético contenido en el ADN de cada célula que hace a cada una de ellas coordinarse con las demás para formar un todo que interactúa con el medio.

El código genético es un sistema de información, y como tal es inmaterial. No se identifica ni con los genes ni con la molécula de ADN que los contiene. Éstas son partes materiales de un organismo organizado a partir de la información inmaterial codificada dentro de ellas. Esto a su vez hace que no haya algo así como un centro de información. La integración por ende no aparece como centralizada en un órgano sino que todo órgano sería algo previsto por la información genotípica. A un organismo humano le corresponde tener un cerebro con ciertas características que permitan el ejercicio de las facultades

22 Platón, Simposio 207d. Sobre la inexactitud de la renovación total véase Oderberg (2005), p 80 n. 22. 
superiores y por eso emerge, junto con muchos otros órganos, en el período embrionario.

Otro punto digno de tenerse en cuenta es el carácter único de la información genética de cada individuo que hace que sea posible establecer, por ejemplo, culpabilidad o inocencia a partir de exámenes de ADN comparando el del acusado con el ADN encontrado en el lugar del crimen. Hasta ahora se pensaba que los gemelos monocigóticos constituirían una excepción a este carácter único, pero aparentemente se ha confirmado que hay diferencias entre ellos, como ya se sospechaba debido a los casos de gemelos monocigóticos de los cuales uno padece, por ejemplo, síndrome de Down y el otro no ${ }^{23}$. Si esto es así podemos afirmar que cada ser humano posee un sistema de información biológica perfectamente único y no repetido.

Esta constatación nos permite concluir que si somos esencialmente organismos dotados de capacidades superiores que requieren necesariamente de un sistema determinado de órganos para funcionar y si la identidad de organismos en el tiempo viene dado por su singular código genético, entonces el criterio de identidad personal será la mismidad genética.

No debe pensarse que esto equivale a un reduccionismo genético pues no nos identificamos con nuestro genoma. Somos seres corporales que mantenemos nuestra identidad en el tiempo por estar activado cada uno de nuestros organismos por su propio y mismo ADN.

La muerte ocurre entonces cuando, por alguna causa o trauma, se interrumpe definitivamente esa función activadora y viene la desintegración. Desgraciadamente no se ha desarrollado aún un modelo de cómo ocurre eso y mucho menos de cómo comprobar que ha ocurrido. En definitiva, no poseemos aún un criterio confiable de muerte en su sentido más estricto, es decir, que permita determinar cuándo la activación genética del organismo en totalidad se detiene. A mi juicio estamos de vuelta a fojas cero por cuanto para determinar el deceso de una persona no tenemos por el momento otra alternativa que la de constatar el efecto de la muerte que se ha invocado desde tiempos inmemoriales: el paro cardio-pulmonar irreversible.

${ }^{23}$ Véase Cummings (2006), pp. 106-107. 


\section{REFERENCIAS BIBLIOGRÁFICAS}

Ad Hoc Committee of the Harvard Medical School (1968): “A Definition of Irreversible Coma”. En Journal of the American Medical Association 205:337-340.

Cummings, M. R. (2006): Human Heredity. Principles and Issues. Belmont: Thomson.

DeGrazia, D. (2005): Human Identity and Bioethics. New York: Cambridge University Press.

Dicker, G. (1993): Descartes. An Analytical and Historical Introduction. New York: Oxford University Press.

Höffe, O. (2005): Aristoteles-Lexikon. Stuttgart: Kröner.

McMahan, J. (2002): The Ethics of Killing. Problems at the Margins of Life. New York: Oxford University Press.

Mollaret, P. y Goulon, M. (1959): “Le Coma Depassé”. En Revue Neurologique 101: 315.

Oderberg, D. (2005): "Hylemorphic Dualism”. En E. F. Paul, F. F. Miller \& J. Paul (comp.), Personal Identity. Cambridge: Cambridge University Press, 70-99.

Olson, E. T. (1997): The Human Animal. Personal Identity Without Psychology. New York: Oxford University Press.

Parfit, S. (1984): Reasons and Persons. Oxford: Oxford University Press.

President's Commission for the Study of Ethical Problems in Medicine and Biomedical and Behavioral Research (1981): Defining Death. Washington, D.C.: United States Printing Office.

President's Council on Bioethics (2009): Controversies in the Determination of Death: A White Paper by the President's Council on Bioethics. Washington, D.C., www.bioethics.gov/reports/death/index.html.

Repertinger, S., W. P. Fitzgibbons, M. F. Omojola y R. A. Brumback (2006): "Long Survival Following Bacterial Meningitis-Associated Brain Destruction”. En Journal of Child Neurology 21(7): 591-595.

Shewmon, A. (1998): “Chronic 'Brain Death.' Meta-analysis and Conceptual Consequences”. En Neurology 51: 1538-1545.

(2001): "The Brain and Somatic Integration: Insights into the Standard Biological Rationale for Equating 'Brain Death' with Death”. En Journal of Medicine and Philosophy 26: 457-478.

Veatch, R. (1993): “The Impending Collapse of the Whole-Brain Definition of Death”. En Hastings Center Report 23(4): 18-24.

Wiggins, D. (2001): Sameness and Substance Renewed. Cambridge: Cambridge University Press. 